\title{
PRECISE CLASSIFICATION OF FOREST SPECIES BASED ON MULTI-SOURCE REMOTE-SENSING IMAGES
}

\author{
ZHANG, R. $.^{1,2}-$ LI, Q. ${ }^{3}-$ DUAN, K. F. ${ }^{4 *}-$ YoU, S. C. ${ }^{1 *}-$ ZHANG, $^{*}{ }^{1}-$ LIU, K. $^{1}-$ GAN, Y. H. ${ }^{1}$ \\ ${ }^{1}$ Land Satellite Remote Sensing Application Center, Ministry of Natural Resources, Beijing \\ 100048, China \\ ${ }^{2}$ College of Resources Environment and Tourism, Capital Normal University, Beijing 100048, \\ China \\ ${ }^{3}$ College of Forestry and Horticulture, Xinjiang Agricultural University, Urumqi 830052, China \\ ${ }^{4}$ School of Economics and Management, Tongji University, Shanghai 200092, China \\ *Corresponding authors \\ e-mail:kefee920729@tongji.edu.cn,youusc@126.com
}

(Received 28 ${ }^{\text {th }}$ Dec 2019; accepted 26 $6^{\text {th }}$ Mar 2020)

\begin{abstract}
Picea schrenkiana var. tianshanica (PSVT) is an endemic tree species in Xinjiang, and serves as windbreak and soil consolidation, to ensure the stability of ecological environment. To efficiently and quickly grasp the ecological status of PSVT and the stability of forest ecosystem, we used images of different resolutions (GF-2 (1 m), GF-1 $(8 \mathrm{~m})$, GF-1 $(16 \mathrm{~m})$, Landsat $8(30 \mathrm{~m}))$ combined with field survey data, and performed multi-resolution segmentation to select the best segmentation scales. Based on the spectrum, texture and terrain factors, the canopy closure inversion of PSVT was performed to select the characteristic factors suitable. Then, we applied three object-oriented methods (i.e. support vector machine (SVM), classification and regression tree (CART), and nearest neighbor classification (NNC)) to classify the forest land. The result shows that the near-infrared (NIR) band is highly independent and makes an important contribution to the optimum index factor (OIF), in which the realtime adjustments of segmentation results are made to achieve better effect. There is a significant relationship between textural features of each band. The canopy closure estimation model performs better with a combination of spectral, terrain, and texture factors. Compared to CART and NNC models, SVM classification achieved better accuracy.
\end{abstract}

Keywords: multi-resolution segmentation, remote sensing, environmental factors, canopy closure, supervised classification

\section{Introduction}

Picea Schrenkiana var. tianshanica (PSVT) is a unique tree species in Xinjiang that is important to the wind resistance, soil stabilization, and overall stability of the ecological environment. The fast and efficient monitoring of forest resource information (Fernandez et al., 2019) and changes has become an important basis for scientific management and the efficient use of forest resources. Canopy closure (Perea et al., 2019; Adepoju et al., 2020), an important aspect of forest information surveys, reflects the growth status and density of forests, and plays a very important role in forest monitoring, so it is widely used in forest resource information surveys and forest ecology evaluations.

With the increasing number of satellite image sources, high-spatial-resolution remote-sensing images now contain more abundant spectral, spatial, shape, and textural information (Abdulhakim, 2019). Using only the spectral information of a single image will very likely cause the problems of "same substance and different spectrum" and 
"different substance and same spectrum" (Gilcher et al., 2019). The reasonable and effective selection of image data sources along with spectral factors, textural information, and terrain factors is very important for ensuring the accuracy and classification of canopy closure. Object-oriented methods can make better use of detailed information regarding an image's spectrum, space, shape, and texture (Baatz, 2000; Hofmann, 2001; Sun, 2009; Guo, 2012). For instance, Baatz (2000) and Hofmann (2001) conducted extensive experiments and research on high-resolution remotesensing images and proposed a method for processing target features and an objectoriented classification. Hofmann (2001) used an object-oriented method to process IKONOS remote-sensing images to effectively classify buildings and highways. Piazza (2016) used aerial imagery to produce a graphic drawing of the tropical rain forest area in southern Brazil, and compared object-oriented and pixel-based classification methods. Guo (2012) took HJ-1 image and used an object-oriented method to effectively classify forest land information in Mentougou district, Beijing. Based on IKONOS images, Sun (2009) used the object-oriented and pixel-based fuzzy classification methods to extract urban-forest-park land in Fuzhou. Data with different resolutions often require different classification methods (Maas, et al., 2019). The canopy closure of a forest stand is used to achieve effective and precise forest classification (Donato et al., 2019), and the relationship between the internal information and depression in images has been widely studied. Linear regression modeling is performed, using the measured value of the degree of sample depression as the dependent variable (Rajasekhar et al., 2019) to obtain the correlation between the image feature factor and the degree of depression. Finally, the precise classification of a forest is realized based on its canopy closure.

In this study, we investigated the effects of spatial resolution on forest classification accuracy and selected the appropriate classification model based on images with different resolutions. Combining field survey data from GF-2 (1 m), GF-1 (8 m), GF-1 $(16 \mathrm{~m})$, and Landsat $8(30 \mathrm{~m})$ images, we established a canopy closure estimation model, selected sensitive feature factors, and used the classification and regression tree (CART), nearest neighbor classification (NNC), and support vector machine (SVM) methods to classify the PSVT. Then, we compared the accuracies of the different classifiers. Our aim in this work was to explore the effect of using data with different spatial resolutions and different classification methods on the precision of forest classification.

\section{Materials and methods}

\section{Study area}

The study area is located in the middle of the Tianshan Mountains (Dilixiati et al., 2019), $110 \mathrm{~km}$ southwest of Urumqi $\left(86^{\circ} 46^{\prime} \mathrm{E}-86^{\circ} 57^{\prime} \mathrm{E}, 43^{\circ} 16^{\prime} \mathrm{N}-43^{\circ} 26^{\prime} \mathrm{N}\right)$. The total forest farm area is approximately $10444 \mathrm{hm}^{2}$ with a woodland core area $5116 \mathrm{hm}^{2}$. The terrain in the study area is complex, with high terrain in the south and low terrain in the north. The altitude ranges between 1700 and $3200 \mathrm{~m}$. Topographic changes are obvious, and the slope mainly ranges between $10^{\circ}$ and $40^{\circ}$. A wide range of rivers flows within the forest farm, with the Toutunhe River flowing from south to north, and small tributaries flowing throughout the area. The drinking water of local herders is mainly from these rivers. The annual precipitation in the study area is unevenly distributed. The annual average precipitation is about $600 \mathrm{~mm}$, with great seasonal differences. The 
concentrated precipitation in summer and autumn accounts for a large proportion of the precipitation over the whole year. The annual average temperature is $3{ }^{\circ} \mathrm{C}$, and the average temperature in July is $14{ }^{\circ} \mathrm{C}$ (Aizezitiyuemaier et al., 2019). The total annual sunshine is $1300 \mathrm{~h}$, and the frost-free period lasts $140 \mathrm{~d}$. Figure 1 shows the specific location of this area, with the forest mainly distributed on the northeast and northwest slopes, comprising mainly grasses and Picea Schrenkiana var. tianshanica (PSVT), and the soil of the forest being ordinary taupe forest soil. As the main dominant conifer species in Xinjiang mountain forests (Li et al., 2019), PSVT comprises an important part of the northern forest. It also plays an irreplaceable role in the conservation of water resources (Liu et al., 2019), maintaining both the water and soil and the ecological balance of the Xinjiang oasis.

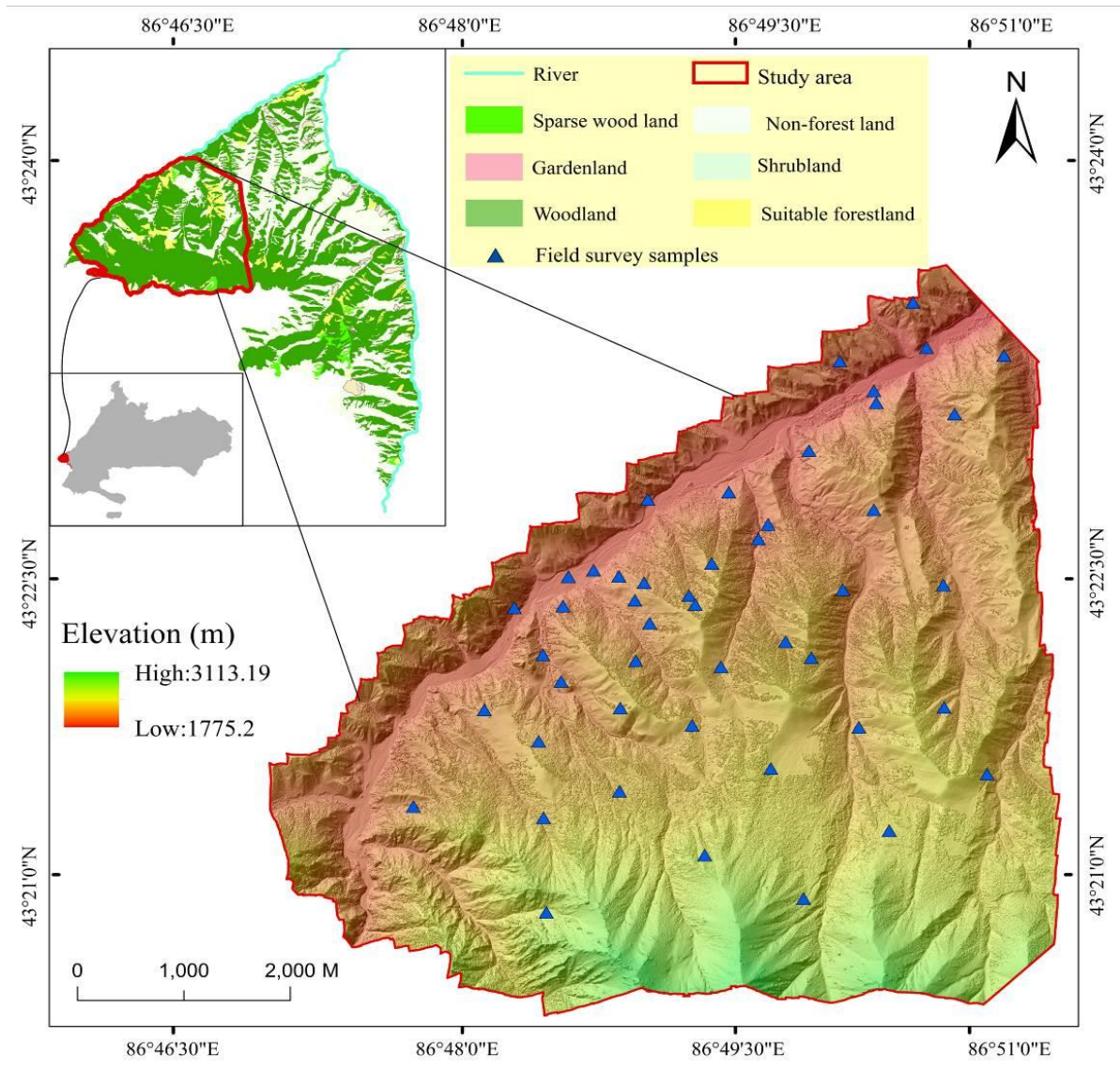

Figure 1. Study area showing study plots and forest types

\section{Data and processing}

\section{Remote sensing data}

Data with different scales reflect the spatial heterogeneity of forest stands. In this study, we used remote-sensing images with four scales, including GF-2 (1 m), GF-1 $(8 \mathrm{~m}), \mathrm{GF}-1(16 \mathrm{~m})$, and Landsat $8(30 \mathrm{~m})$. According to multispectral satellite imagery data in the study area (Table 1), we performed extensive pre-processing, including radiometric calibration, atmospheric correction, orthorectification, projection definition, cropping, and image fusion. We then used these satellite remote-sensing images to invert the canopy closure for classification experiments. 
Table 1. Main parameters of satellite images

\begin{tabular}{|c|c|c|c|c|c|c|c|}
\hline Type & Payload & Band & $\begin{array}{c}\text { Spectral } \\
\text { range }(\mu \mathrm{m})\end{array}$ & \begin{tabular}{|c|} 
Spatial \\
resolution $(\mathrm{m})$ \\
\end{tabular} & $\begin{array}{c}\text { Width } \\
(\mathbf{k m})\end{array}$ & $\begin{array}{c}\text { Revisit } \\
\operatorname{period}(d)\end{array}$ & $\begin{array}{c}\text { Acquisition } \\
\text { time }\end{array}$ \\
\hline \multirow{9}{*}{ GF-1 } & \multirow{5}{*}{ PMS } & 1 & $0.45 \sim 0.52$ & 8 & \multirow{5}{*}{60} & \multirow{5}{*}{4} & \multirow{5}{*}{$3 / 8 / 2017$} \\
\hline & & 2 & $0.52 \sim 0.59$ & 8 & & & \\
\hline & & 3 & $0.63 \sim 0.69$ & 8 & & & \\
\hline & & 4 & $0.77 \sim 0.89$ & 8 & & & \\
\hline & & Panchromatic & $0.45 \sim 0.90$ & 2 & & & \\
\hline & \multirow{4}{*}{ WFV } & 1 & $0.45 \sim 0.52$ & 16 & \multirow{4}{*}{800} & & \multirow{4}{*}{$16 / 8 / 2017$} \\
\hline & & 2 & $0.52 \sim 0.59$ & 16 & & & \\
\hline & & 3 & $0.63 \sim 0.69$ & 16 & & & \\
\hline & & 4 & $0.77 \sim 0.89$ & 16 & & & \\
\hline \multirow{5}{*}{ GF-2 } & & 1 & $0.45 \sim 0.52$ & 2.4 & \multirow{5}{*}{45} & \multirow{5}{*}{5} & \multirow{5}{*}{$3 / 8 / 2017$} \\
\hline & & 2 & $0.52 \sim 0.59$ & 2.4 & & & \\
\hline & & 3 & $0.63 \sim 0.69$ & 2.4 & & & \\
\hline & & 4 & $0.77 \sim 0.89$ & 2.4 & & & \\
\hline & & Panchromatic & $0.45-0.90$ & 0.61 & & & \\
\hline \multirow{11}{*}{ Landsat 8} & \multirow{9}{*}{ OLI } & 1 & $0.43 \sim 0.45$ & 30 & \multirow{9}{*}{185} & \multirow{9}{*}{16} & \multirow{9}{*}{ 4/8/2017 } \\
\hline & & 2 & $0.45 \sim 0.52$ & 30 & & & \\
\hline & & 3 & $0.53 \sim 0.60$ & 30 & & & \\
\hline & & 4 & $0.63 \sim 0.68$ & 30 & & & \\
\hline & & 5 & $0.85 \sim 0.89$ & 30 & & & \\
\hline & & 6 & $1.56 \sim 1.66$ & 30 & & & \\
\hline & & 7 & $2.10 \sim 2.30$ & 30 & & & \\
\hline & & 8 & $0.50 \sim 0.68$ & 15 & & & \\
\hline & & 9 & $1.36 \sim 1.39$ & 30 & & & \\
\hline & \multirow{2}{*}{ TIRS } & 10 & $10.6 \sim 11.2$ & 100 & & & \\
\hline & & 11 & $11.5 \sim 12.5$ & 100 & & & \\
\hline
\end{tabular}

\section{Field survey data}

The field data mainly included data from 47 plots with the dimensions $30 \mathrm{~m} \times 30 \mathrm{~m}$ surveyed from July to September 2017 (Fig. 2), including their latitudes and longitudes, along with their wooden height, crown width, slope, aspect, elevation, and canopy closure. We used GPS to record the center point of the sample square and the positions of the four corner points and matched the measured sample plots with the corresponding remote-sensing images. The measurement process of the canopy closure was as follows: First, we set the sample points and captured images of five crowns with the Win SCANOPY canopy analyzer, include center point, 2 diagonal lines formed by southeastnorthwest and northeast-southwest. Then, we used Win SCANOPY 2016 software to calculate the light transmission porosity of the five canopy images, using the mean value as the true value of the measured light transmittance in the ground field. To eliminate the influence of shrubs and weeds on the canopy measurements, we set the height of the fisheye lens to $1.5 \mathrm{~m}$. Using the Win SCANOPY 2016 software to analyze the fisheye photos, we obtained two measures of light transmittance porosity, the gap fraction and the openness. The openness measure eliminates the effect of nonlinear projection on the transparency of the canopy to generate a result equal to the true canopy transparency. Therefore, we used the openness measure as the canopy transparency. 

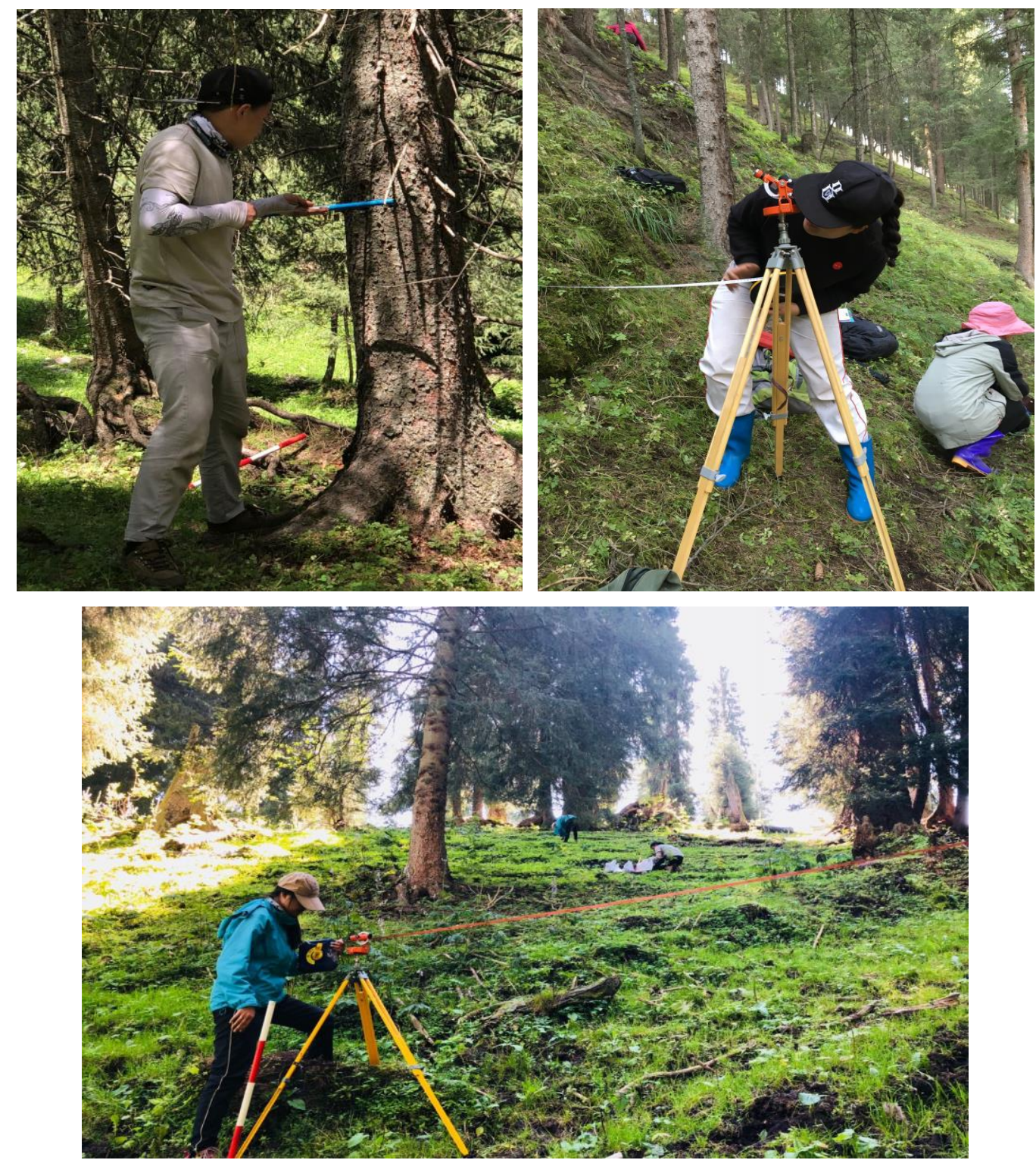

Figure 2. Field survey of PSVT in Tianshan Mountain

\section{Methods}

\section{Multi-scale segmentation}

Multi-scale segmentation, an algorithm based on region segmentation, performs bottom-up segmentation of target image data. The objective is to gather one or more groups of pixels with similar features to identify a set of regions and thereby obtain different image objects as carriers for the next image classification. In the process of segmentation, a different level of network structure is established and each segmentation is based on the image object layer of the following layer for segmentation, which is then merged in the segmentation process. The segmentation parameters mainly include the segmentation scale and weight factor. Spectral and shape factors and smoothness and tightness factors are two important pairs of parameters in multi-scale segmentation. The sum of the spectral and shape factors is equal to 1 , and that of the 
smoothness and tightness factor is also 1, so the reasonable adjustment of parameters has an important impact on multi-scale segmentation.

\section{Best factor index (OIF) method}

We used the best factor index (OIF) method (Goodchild, 1995; Singh, 2013) to select the bands of the GF-2 $(1 \mathrm{~m})$, GF-1 $(8 \mathrm{~m})$, GF-1 $(16 \mathrm{~m})$, and Landsat $8(30 \mathrm{~m})$ images. By calculating the standard deviation of each of the four types of data and the correlation coefficients between the bands, we could select the band combination most suitable for the region. This is because the standard deviation indicates the amount of information contained, and the correlation coefficient between each band reflects the independence of the image data and their degree of redundant information. To calculate the OIF, we use Equation 1:

$$
0 I F=\frac{\sum_{i=1}^{n} Y_{i}}{\sum_{i=1}^{n} \sum_{j=i+1}^{n}\left|Y_{i j}\right|}
$$

where $n$ is the band of the remote-sensing images, $Y_{i}$ is the standard deviation of each band, and $\mathrm{Y}_{\mathrm{ij}}$ is the correlation coefficient between band $\mathrm{i}$ and band $\mathrm{j}$.

\section{Principal component analysis (PCA)}

We used the PCA algorithm to reduce the number and dimensions of the feature factors and improve processing efficiency (Lin et al., 2004). First, we analyzed the correlation between individual feature factors, after which we used the variance matrix to orthogonally rotate the load matrix of the feature factors and select the factors with a load factor of 0.85 or higher in each principal component. The selected feature factors were then used as independent variables to construct the canopy-closure estimation model. PCA not only ensures that unrelated comprehensive factors can be extracted to minimize the loss of information, but also reduces the spatial dimensions.

\section{Multiple stepwise regression}

Multivariate stepwise linear regression is the basic modeling method used in regression modeling, whereby the model selects the variable $\mathrm{x}_{1}$ that has the most significant effect on the dependent variable among all the $\mathrm{n}$ independent variables. Then it selects the variable $\mathrm{x}_{2} \ldots \mathrm{x}_{1}$ with the most significant effect on the dependent variable among the remaining $\mathrm{n}-1$ independent variables. In this way, $\mathrm{x}_{2} \ldots \mathrm{x}_{\mathrm{n}}$ establishes $\mathrm{a}$ multivariate equation, and another multivariate equation is established for significant $\mathrm{x}_{1}$, $\mathrm{x}_{2}, \ldots \mathrm{x}_{\mathrm{m}}$ variables. Next, the model selects and verifies all the independent variables that have a significant effect on the dependent variable. The multivariate stepwise linear regression equation (Eq. 2) is:

$$
\mathrm{y}=\mathrm{k}+\mathrm{ax}_{1}+\mathrm{bx}_{2}+\mathrm{cx}_{3}+\ldots+\mathrm{nx}_{\mathrm{m}}
$$

where $\mathrm{k}$ is a regression constant term, $\mathrm{a}, \mathrm{b}, \mathrm{c} \ldots \mathrm{n}$ are the regression coefficients, and $\mathrm{x}_{1}$, $\mathrm{x}_{2}, \ldots \mathrm{x}_{\mathrm{m}}$ are the significant independent variables. 


\section{Classification method and accuracy evaluation}

We used three methods to classify forest land and compare the classification results (Wang et al., 2019; Wei et al., 2019), including CART, NNC, and SVM. CART, a common classification method (Cai et al., 2019), uses the Gini Index to select the best test variable. It achieves fast classification and has strong practicability. NNC classifies by determining the distance between sample objects, with the degree of membership of a sample determining the classification accuracy. SVM improves the generalization ability of a model by reducing the amount of sample error by transforming the sample space into a high-dimensional space and then constructing an optimal classification hyperplane as the decision surface. In this study, we correlated the main evaluation indicators, i.e., overall accuracy, mapping accuracy, and user accuracy, based on the confusion matrix method. Using the coefficient of determination $\left(\mathrm{R}^{2}\right)$, root mean square difference (RMSE) (Eq. 3), and estimation accuracy (EA\%) (Eq. 4), we could determine the accuracy of the different types of canopy-closure models, and using the confusion matrix to calculate classification accuracy, include overall accuracy (OA) (Eq. 5), user accuracy (UA) (Eq. 6), and producer accuracy (PA) (Eq. 7).

$$
\begin{aligned}
\text { RMSE } & =\sqrt{\frac{\sum_{i=1}^{\mathrm{n}}\left(\mathrm{s}_{\mathrm{i}}-\mathrm{y}_{\mathrm{i}}\right)^{2}}{\mathrm{n}}} \\
\mathrm{EA}=\left(1-\frac{\mathrm{RMSE}}{\operatorname{Ave}\left(\mathrm{y}_{\mathrm{i}}\right)}\right) \times 100 \% & \\
\mathrm{OA} & =\frac{\mathrm{TP}+\mathrm{TN}}{\mathrm{T}} \\
\mathrm{UA} & =\frac{\mathrm{TP}}{\mathrm{TP}+\mathrm{FP}} \\
\mathrm{PA} & =\frac{\mathrm{TP}}{\mathrm{TP}+F N}
\end{aligned}
$$

$\mathrm{y}_{\mathrm{i}}, \mathrm{S}_{\mathrm{i}}$ represent the measured and estimated values, respectively; $\operatorname{Ave}\left(\mathrm{y}_{\mathrm{i}}\right)$ are the average values of the samples, and $n$ is the number of samples; TP is the correctly extracted objects; FP is the incorrectly extracted objects; TN is the non-samples that are correctly rejected; FN is the samples that are not detected.

\section{Results}

\section{Canopy features extraction}

\section{Vegetation index factor}

When considering the spectral features (Twisa and Buchroithner, 2019; Brabant et al., 2019), we selected three vegetation indices, the ratio vegetation index (RVI), 
normalized vegetation index (NDVI), and the transformed normalized difference vegetation index (TNDVI) (Table 2). The RVI changes significantly with changes in the vegetation coverage. When the coverage exceeds or is lower than $50 \%$, the sensitivity of the RVI to vegetation increases or decreases, which reflects the vegetation coverage. NDVI, which is derived from RVI by simple nonlinear normalization, reflects the growth of the vegetation and the effective coverage, and effectively eliminates the influence of atmospheric radiation to show the same trend as shown by the vegetation coverage (Fig. 3). TNDVI is mainly used to adjust the NDVI when the sensitivity of the vegetation coverage is higher or lower, and it more intuitively reflects the comprehensive condition and growth of vegetation.

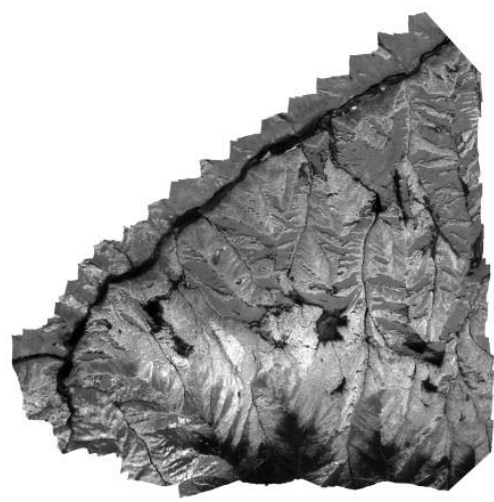

(a)

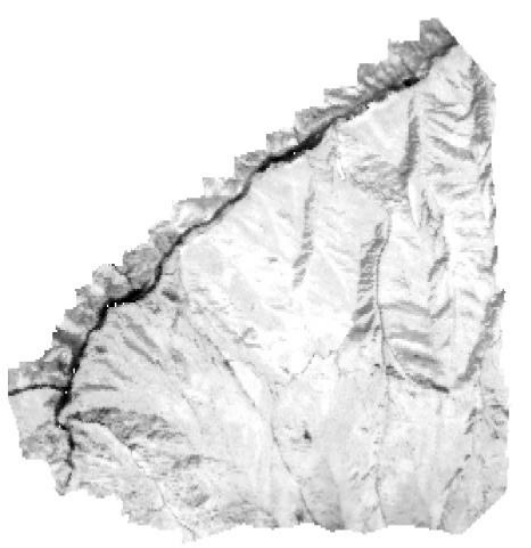

(c)

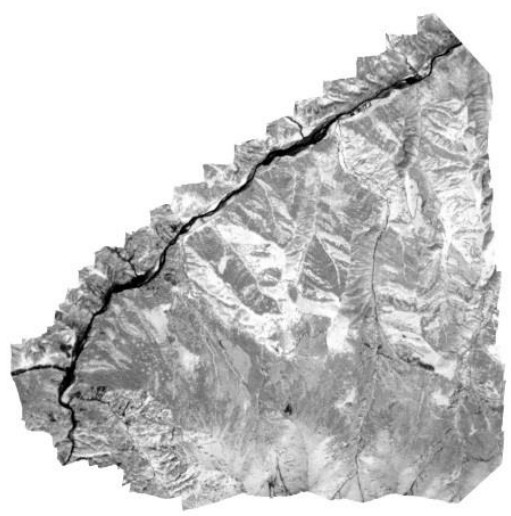

(b)

high: 1

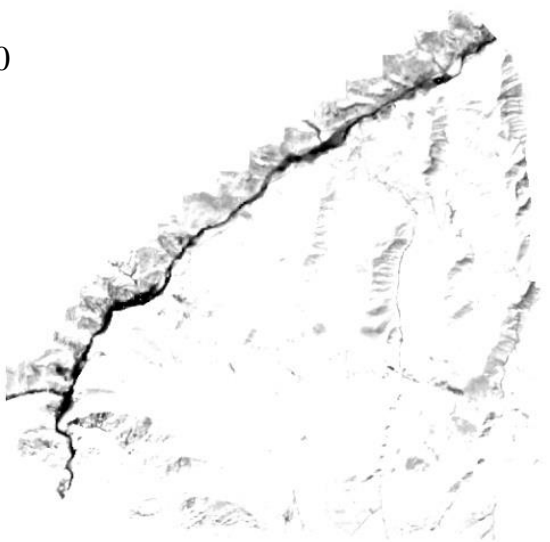

(d)

Figure 3. Vegetation index features of remote-sensing images. (a) GF-2 (1 m); (b) GF-2 (8 m); (c) GF-2 (16 m); (d) Landsat 8 OLI $(30 \mathrm{~m})$

\section{Terrain and shadow index factor}

Due to the height angle of the sun, the height of the object itself, and the varied topography in the study area, a remote-sensing image will contain more shadows, which can affect the estimation of the canopy closure in the study area. Using ENVI 5.3 software, we found the slope, slope direction, and height of the study area to have a direct impact on the canopy closure of the stand and the extraction of the shadow index, 
slope, aspect, and height of the image. In particular, the shadow index is the ratio of the fourth to the third band based on the image data.

Table 2. Alternative factors for vegetation index

\begin{tabular}{c|c}
\hline Modeling factor & Calculation formula \\
\hline Ratio vegetation index (RVI) & $\mathrm{RVI}=\frac{\mathrm{DN}_{\mathrm{NIR}}}{\mathrm{DN}}$ \\
Normalized vegetation index (NDVI) & $\mathrm{NDVI}=\frac{\mathrm{NIR}-\mathrm{R}}{\mathrm{NIR}+\mathrm{R}}$ \\
Conversion vegetation index (TNDVI) & $\mathrm{TNDVI}=\sqrt{\frac{\mathrm{DN}_{\mathrm{NIR}}-\mathrm{DN}_{\mathrm{R}}}{\mathrm{DN}_{\mathrm{NIR}}+\mathrm{DN}_{\mathrm{R}}+0.5}}$ \\
\hline
\end{tabular}

R: Red band; NIR: Near infrared band

\section{Texture factors}

The simple use of spectral features will result in a large loss of spatial information of the image, whereas the addition of textural features can make full use of the spatial information. In the same kind of remote-sensing images, the textural features of different canopy regions can differ, with the texture of a canopy with a larger canopy closure being more uniform and that with a smaller canopy closure being less uniform. Choosing the right type of textural feature will greatly improve the accuracy of canopy estimation. The gray level co-occurrence matrix (GLCM) (Haralick, 1973) describes the correlation and spatial structures of pixel pairs based on the spatial relationship of the gray values of an image. GLCM is the most commonly used method used for textural analysis. In this study, we used the GLCM to extract eight textural features from Tianshan spruce forest images in the study area. Figure 4 shows the specific textural feature factors and extraction results.
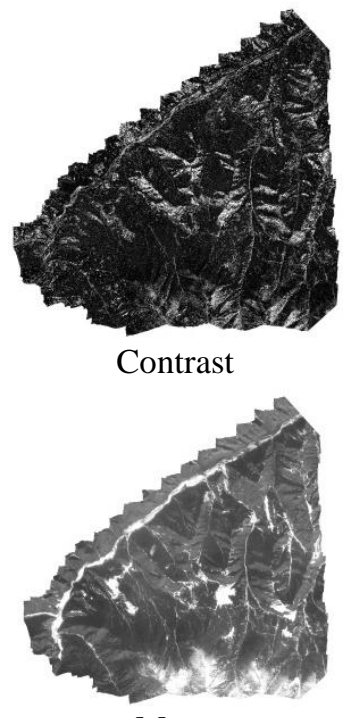

Mean

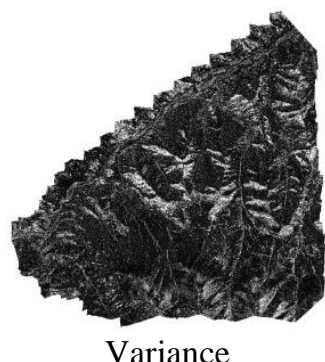

Variance

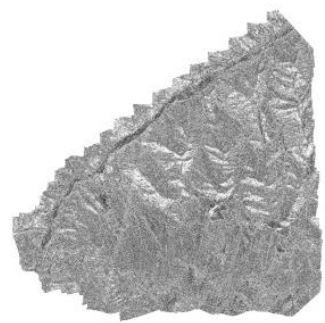

Correlation

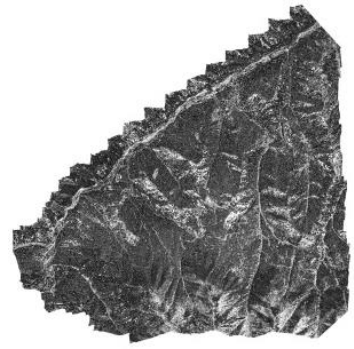

Dissimilarity

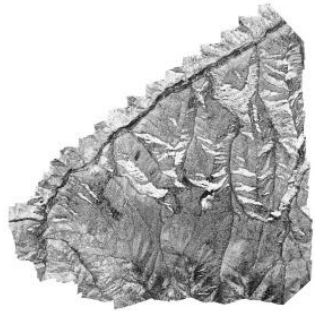

Homogeneity

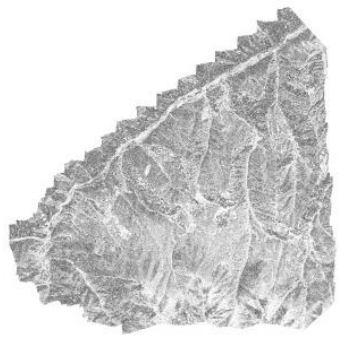

Entropy

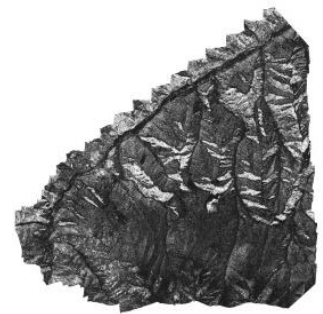

Second moment

Figure 4. Textural features of band 1 of GF-2 remote-sensing image 


\section{Multi-resolution segmentation}

Each band of multispectral remote-sensing data with different spatial resolutions contains different amounts of information. Using the weight ratio method, the spectral information of these different bands can be biased or discarded to improve the segmentation efficiency and effect of different remote-sensing images. In this study, we used the OIF method to compare and screen the bands by calculating the standard deviation of each band and the correlation coefficient between bands in the remotesensing images with different spatial resolutions. When the standard deviation between the bands is larger, the correlation coefficient between the bands will be smaller, and the more information is contained in the band, the stronger is the independence of the data.

In Table 3 we can see that for band combination GF-2 $(1 \mathrm{~m})$, the highest OIF value is the combination with band 234. Compared to the band combinations 123,124, and 1234 , it can be seen that when the 1st and 2nd bands are fixed, the 4th band is introduced, and the OIF value is increased from 64.357 to 74.392 , and when the 234 band combination is fixed, band 1 is introduced to the band combination, and the OIF value is reduced from 78.665 to 67.15 . For GF-1 images $(8 \mathrm{~m})$, when the first and second bands are fixed, the fourth band is introduced, and the OIF value does not change significantly. When the band combination 234 is fixed, band 1 is introduced to the band combination, and the obtained OIF value is significantly reduced from 69.014 to 55.134. For GF-1 images $(16 \mathrm{~m})$, when the $1 \mathrm{st}$ and 2 nd bands are fixed, the 4th band is introduced, and the OIF value does not increase significantly. When the band combination 234 is fixed, band 1 is introduced to the band combination, and the obtained OIF value is significantly reduced from 68.836 to 47.402 . For Landsat 8 images $(30 \mathrm{~m})$, in the band combination (Table 4), the combination of the 146th and 456th bands has a higher OIF value.

Table 3. GF data OIF values of each combination band

\begin{tabular}{c|c|c|c|c|c}
\hline Combined band & $\mathbf{1 2 3}$ & $\mathbf{1 2 4}$ & $\mathbf{1 3 4}$ & $\mathbf{2 3 4}$ & $\mathbf{1 2 3 4}$ \\
\hline GF-2 $(1 \mathrm{~m})$ & 64.357 & 74.392 & 76.811 & 78.665 & 67.165 \\
GF-1 $(8 \mathrm{~m})$ & 51.233 & 52.736 & 59.236 & 69.014 & 55.134 \\
GF-1 $(16 \mathrm{~m})$ & 44.987 & 47.496 & 57.246 & 68.836 & 47.402 \\
\hline
\end{tabular}

Table 4. Landsat 8 data (30 m) OIF values of each combination band

\begin{tabular}{c|c|c|c}
\hline Combined band & OIF value & Combined band & OIF value \\
\hline 124 & 45.714 & 234 & 51.012 \\
125 & 47.175 & 235 & 49.674 \\
126 & 63.411 & 236 & 69.563 \\
127 & 28.622 & 237 & 31.552 \\
134 & 48.259 & 245 & 77.243 \\
135 & 49.489 & 247 & 47.701 \\
136 & 66.268 & 256 & 103.057 \\
137 & 30.522 & 257 & 46.752 \\
145 & 73.640 & 345 & 73.134 \\
146 & 105.206 & 346 & 95.913 \\
147 & 44.188 & 347 & 45.584 \\
157 & 45.919 & 456 & 100.173 \\
167 & 63.410 & 457 & 67.020 \\
\hline
\end{tabular}


In short, for remote-sensing image data with different resolutions, the image information contained in the near-infrared band is rich, the image information contained in this band is relatively independent, and the contribution to the OIF is also obvious. In addition, to extract forest land information, the near-infrared band shows high reflectivity of the vegetation, which has obvious benefit for the extraction of forest land information. When setting the weight of the split band and the weights of the GF-2 (1 m), GF-1 (8 m), and GF-1 (16 m) bands, we set the data to 0 (band 1), 1 (band 2), 1 (band 3), and 2 (band 4). For Landsat 8 (30 m), we set each band weight to 0 (band 1), 1 (band 2), 0 (band 3), 1 (band 4), 2 (band 5), 2 (band 6), and 1 (band 7).

In the multi-resolution segmentation process, the segmentation scale can either too small or too large, which will affect the accuracy of the target object classification. As such, it is important to set the optimal segmentation scale for different image data in the target region to ensure that the multi-resolution segmentation can effectively segment different remote-sensing data, which lays the foundation for information extraction and classification of different images. Depending on the target of the extracted features, the types of bands involved in the segmentation will differ, so no single classification method can be used. Using eCognition Developer 9.0, we scaled and processed the remote-sensing data with four different resolutions, and intercepted some regions with richer terrestrial types to compare the segmentation effects of different data sources, categories, and scales.

In terms of GF-2 $(1 \mathrm{~m})$, GF-1 $(8 \mathrm{~m}), \mathrm{GF}-1(16 \mathrm{~m})$, and Landsat $8(30 \mathrm{~m})$, we set the segmentation scale from 90, 65, 30, and 20 respectively (Zhang et al., 2015), with a step size of 5 , and simultaneously set the compactness and smoothness of the remote sensing data with different resolutions to be 0.5 , to study and analyze the spectrum and shape factors. Specifically, the compactness value is set to be 0.5 (remain unchanged), the initial value of the shape factor is set to 0.1 , and we increase the shape factor from 0.1 to 0.8 with a step size of 0.1 , to conduct the multi-scale segmentation experiments in turn (Zhang et al., 2014). After several experimental comparisons, we obtained the optimal segmentation scales for GF-2 (1 m), GF-1 $(8 \mathrm{~m})$, GF-1 $(16 \mathrm{~m})$, and Landsat $8(30 \mathrm{~m})$, which are $115,85,55$, and 35 , respectively. We set the shape and compactness of the weighting factors to $0.3,0.5$, $0.3,0.5,0.5,0.6,0.2$, and 0.5, respectively, and achieved superior results for each image (Fig. 5). The results indicate that the topography of the study area comprises mostly natural landforms, and that most of the features are Tianshan spruce forest land and grassland, which means the shape factor accounts for only a small proportion and the spectral factor accounts for a large proportion.

With respect to the band weights of the remote-sensing image bands, during the segmentation process, we set different band weights for different remote-sensing data from the same research area. In this study, we calculated the standard deviation and correlation coefficient of each band based on remote-sensing data with different spatial resolutions, and used the OIF value to determine the best combination of bands for performing image segmentation. From the analysis, we found that the combination of different bands of the remote-sensing images with the same resolution and the same bands of images with different resolutions yielded different OIF values. The correlation coefficient is relatively small between the near-infrared band (NIR) and other bands in the remote-sensing image data. The independence of the band information is also strong, and the contribution rate to the OIF value is also large. When segmenting the Tianshan spruce forest based on GF-2 $(1 \mathrm{~m})$ remote-sensing 
data, when the weights of the first, second, third, and fourth bands are set to $0,1,1$, and 2, respectively, and the division scale, shape, and compactness factor are respectively set to $115,0.3$, and 0.5 , the obtained segmentation result is optimal. For GF-1 ( $8 \mathrm{~m})$, when the weights of the $1 \mathrm{st}, 2 \mathrm{nd}, 3 \mathrm{rd}$, and 4 th bands are set to $0,1,1$, and 2 , respectively, and the division scale, shape, and compactness factors are set to 85 , 0.3 , and 0.5 , the best image segmentation is obtained. For GF-1 (16 m) data, we set the weights of the first, second, third, and fourth bands to $0,1,1$, and 2, respectively, the scale selection to 55, and the shape and compactness factors are to 0.5. At 0.6, the segmentation results are the best. For Landsat $8(30 \mathrm{~m})$ remote-sensing images, we set the weights of the 1st, 2nd, 3rd, 4th, 5th, 6th, and 7th bands to 0, 1, 0, 1, 2, 2, and 1, respectively. When the shape and the compactness factor are 0.2 and 0.5 , the image segmentation effect is the best.

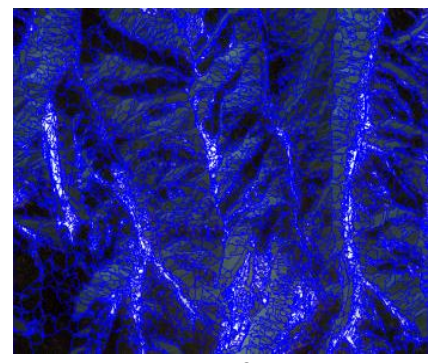

$\mathrm{a}_{1} 90$

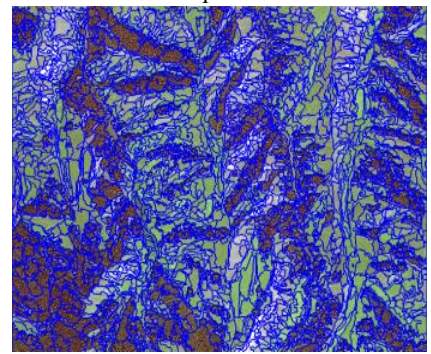

$b_{1} 65$

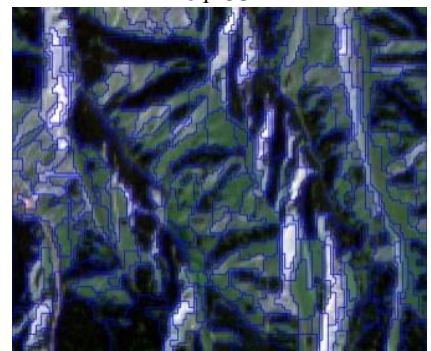

$\mathrm{c}_{1} 30$

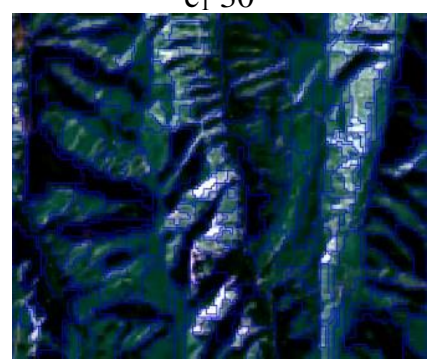

$\mathrm{d}_{1} 20$

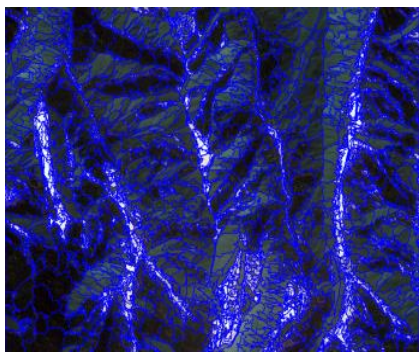

$\mathrm{a}_{2} 115$

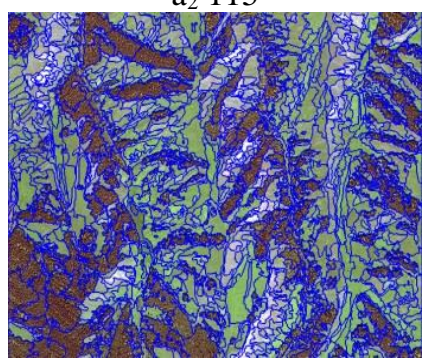

$\mathrm{b}_{2} 85$

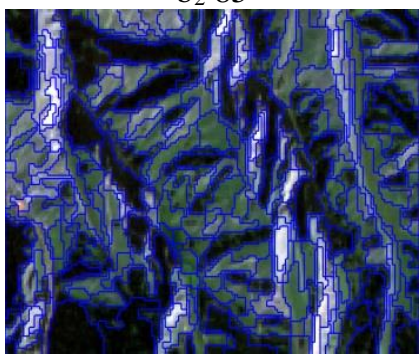

$c_{2} 55$

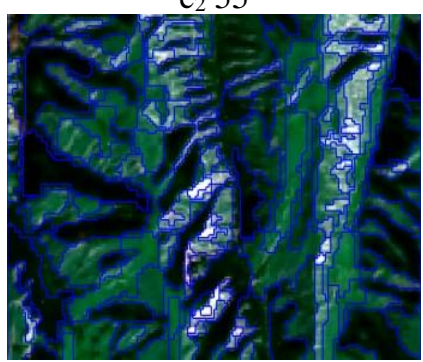

$\mathrm{d}_{2} 35$

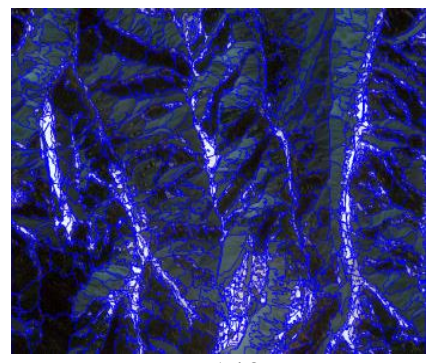

$\mathrm{a}_{3} 140$

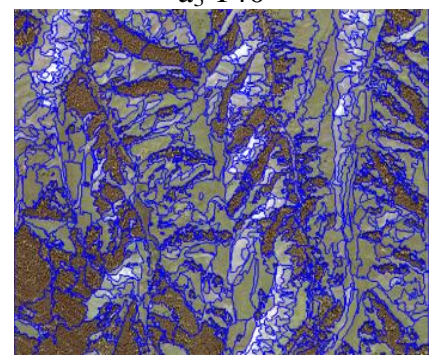

$b_{3} 110$

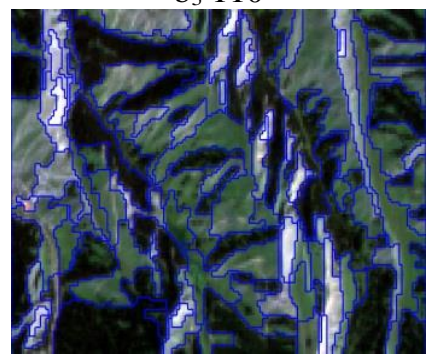

$c_{3} 80$

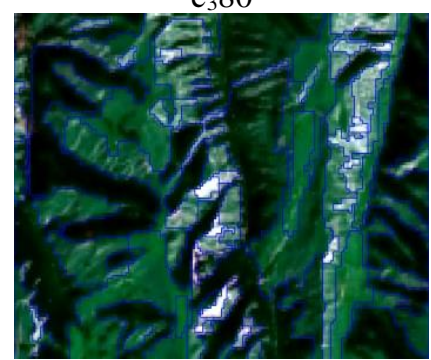

$\mathrm{d}_{3} 60$

Figure 5. Maps of multi-scale segmentation effects of remote-sensing data with different resolutions. $a_{1}, a_{2}, a_{3}$ are GF-2 ( $\left.1 \mathrm{~m}\right)$ images, $b_{1}, b_{2}, b_{3}$ are GF- $1(8 \mathrm{~m})$ images, $c_{1}, c_{2}, c_{3}$ are GF$1(16 \mathrm{~m})$ images, $d_{1}, d_{2}, d_{3}$ are Landsat $8(30 \mathrm{~m})$ images 


\section{Canopy closure simulation}

Next, we conducted an experiment using the GF-2 (1 m), GF-1 (8 m), GF-1 (16 m), and Landsat $8(30 \mathrm{~m})$ images. Using the image and feature factor variables, we constructed a canopy-closure estimation model based on the measured values of the canopy closure in the field, and then evaluated its accuracy. We calculated 39 features related to the spectra, texture, shape, topography, and shadow index. Spectral factors included the NDVI, RVI, TNDVI, SI; topographic factors including the slope, aspect, and altitude; and textural factors including the mean, variance, homogeneity, contrast, dissimilarity, entropy, second moment, and correlation. Using SPSS 19.0 software, we performed correlation analysis of the 39 extracted feature factors and the measured canopy-closure values, and selected the factors with a small correlation. As independent variables, we used spectral and topographical features, textural features, spectral and topographic features + textural features, and used canopy closure as the dependent variable. We used the multi-step regression method to construct the canopy closure model. In Table 5, the fit of the canopy-closure regression model based on the spectral, topographic features and texture features is significantly better than that achieved when using a single spectrum, topographical features, or textural features. $\mathrm{R}^{2}$ and corrected $\mathrm{R}^{2}$ reflect degree of advantages for simulation results.

Table 5. Estimation models of canopy density of spruce in Picea Schrenkiana var tianshanica based on different characteristic factors

\begin{tabular}{|c|c|c|c|c|}
\hline Type & Variable & Estimation model & $R^{2}$ & Correction $R^{2}$ \\
\hline \multirow{4}{*}{ Spectral } & $\begin{array}{l}\text { SI, Slope } \\
(\text { GF-1 } 2 \mathrm{~m})\end{array}$ & $\mathrm{y}=1.123-2.256 \times$ SI- $0.004 \times$ Slope & $0.671 * *$ & 0.643 \\
\hline & $\begin{array}{l}\text { SI, NDVI, RVI } \\
\text { (GF-1 } 8 \text { m) }\end{array}$ & $\mathrm{y}=0.772+2.398 \times \mathrm{NDVI}-0.636 \times \mathrm{RVI}-0.638 \times \mathrm{SI}$ & $0.602 * *$ & 0.594 \\
\hline & $\begin{array}{l}\text { TNDVI, RVI, NDVI } \\
\quad(\text { GF-1 } 16 \mathrm{~m})\end{array}$ & $\mathrm{y}=1.205-1.438 \times \mathrm{NDVI}-0.152 \times \mathrm{RVI}-0.996 \times \mathrm{TNDVI}$ & $0.573^{* *}$ & 0.558 \\
\hline & $\begin{array}{l}\text { SI, RVI, NDVI } \\
\text { (OLI } 30 \mathrm{~m})\end{array}$ & $\mathrm{y}=0.867+0.606 \times \mathrm{NDVI}-0.245 \times \mathrm{RVI}-0.526 \times \mathrm{SI}$ & $0.573 * *$ & 0.558 \\
\hline \multirow{4}{*}{ Texture } & $\begin{array}{c}\mathrm{Con}_{1}, \mathrm{Con}_{2}, \mathrm{Con}_{3}, \mathrm{Con}_{4}, \\
\mathrm{Ent}_{3}, \mathrm{SeM}_{3} \\
(\mathrm{GF}-12 \mathrm{~m})\end{array}$ & $\begin{array}{c}\mathrm{y}=5.280-0.394 \times \mathrm{Con}_{2}+0.129 \times \mathrm{Con}_{4}+0.125 \times \mathrm{Con}_{3}+0.236 \times \mathrm{Con}_{1}- \\
2.143 \times \mathrm{Ent}_{3}-4.929 \times \mathrm{SeM}_{3}\end{array}$ & $0.774 * *$ & 0.759 \\
\hline & $\begin{array}{c}\mathrm{M}_{4}, \mathrm{Va}_{4}, \mathrm{Dis}_{1}, \mathrm{Dis}_{2}, \mathrm{Dis}_{3} \\
(\mathrm{GF}-18 \mathrm{~m})\end{array}$ & $\begin{array}{c}\mathrm{y}=0.646+0.091 \times \mathrm{Dis}_{3}-0.045 \times \mathrm{Dis}_{2}+0.012 \times \mathrm{Dis}_{1^{-}} \\
0.006 \times \mathrm{Va}_{4}+0.010 \times \mathrm{M}_{4}\end{array}$ & $0.623 * *$ & 0.604 \\
\hline & $\begin{array}{l}\mathrm{M}_{4}, \mathrm{Va}_{4}, \mathrm{Dis}_{1}, \mathrm{Dis}_{2}, \mathrm{Dis}_{3} \\
(\mathrm{GF}-116 \mathrm{~m})\end{array}$ & $\begin{array}{c}\mathrm{y}=0.646+0.091 \times \mathrm{Dis}_{3}-0.045 \times \mathrm{Dis}_{2}+0.012 \times \mathrm{Dis}_{1}- \\
0.006 \times \mathrm{Va}_{4}+0.010 \times \mathrm{M}_{4}\end{array}$ & $0.623 * *$ & 0.604 \\
\hline & $\begin{array}{c}\mathrm{M}_{7}, \mathrm{Ent}_{2} \\
(\mathrm{OLI} 30 \mathrm{~m}) \\
\end{array}$ & $\mathrm{y}=0.859-0.147 \times \mathrm{Ent}_{2}+0.233 \times \mathrm{M}_{7}$ & $0.623 * *$ & 0.604 \\
\hline \multirow{4}{*}{$\begin{array}{c}\text { Spectral } \\
+ \\
\text { texture }\end{array}$} & $\begin{array}{l}\text { SI, } \mathrm{Con}_{2}, \mathrm{Con}_{3}, \mathrm{Con}_{4} \\
(\mathrm{GF}-12 \mathrm{~m})\end{array}$ & $\mathrm{y}=1.355-4.936 \times \mathrm{SI}+0.232 \times \mathrm{Con}_{3}-0.271 \times \mathrm{Con}_{2}+0.091 \times \mathrm{Con}_{4}$ & $0.823^{* *}$ & 0.797 \\
\hline & $\begin{array}{l}\text { SI, NDVI, Slope, } \mathrm{M}_{4} \\
(\text { GF-1 } 8 \mathrm{~m})\end{array}$ & $\begin{array}{c}\mathrm{y}=0.480+6.265 \times \mathrm{SI}-0.054 \times \mathrm{M}_{4^{-}} \\
0.005 \times \text { Slope }+0.208 \times \text { Cor }_{4}+0.808 \times \mathrm{NDVI}\end{array}$ & $0.724 * *$ & 0.701 \\
\hline & $\begin{array}{c}\text { SI, TNDVI, } \mathrm{Dis}_{1}, \mathrm{Dis}_{2}, \\
\mathrm{Dis}_{3}, \mathrm{Va}_{4} \\
(\mathrm{GF}-116 \mathrm{~m}) \\
\end{array}$ & $\begin{array}{c}\mathrm{y}=0.270+3926 \times \mathrm{SI}_{-} 0.006 \times \mathrm{Va}_{4}-0.052 \times \mathrm{Dis}_{2-}- \\
0.008 \times \mathrm{Dis}_{1}+0.118 \times \mathrm{Dis}_{3}+0.426 \times \mathrm{TNDVI}^{-}\end{array}$ & $0.654 * *$ & 0.691 \\
\hline & $\begin{array}{l}\text { TNDVI, } \mathrm{M}_{7}, \mathrm{Cor}_{1}, \mathrm{Ent}_{2} \\
\quad(\mathrm{OLI} 30 \mathrm{~m})\end{array}$ & $\mathrm{y}=0.859+0.076 \times$ Cor $_{1}-0.141 \times$ Ent $_{2}-0.070 \times \mathrm{TNDVI}+0.224 \times \mathrm{M}_{7}$ & $0.654 * *$ & 0.691 \\
\hline
\end{tabular}

SI: Shadow index; **represents significantly correlated at the 0.01 level $(\mathrm{P}<0.01)$; *represents significantly correlated at the 0.05 level ( $\mathrm{P}<0.05)$; M, Va, H, Con, Dis, Ent, SeM, Cor represent mean, variance, homogeneity, contrast, dissimilarity, entropy, second moment, correlation, respectively. The subscripts 1, 2, 3, 4, 5, 6, and 7 represent the B1, B2, B3, B4, B5, B6, and B7 bands, respectively 
To test the universality of the estimated model, we tested its accuracy. The remaining 15 test samples were used in three regression models to obtain predicted canopy-closure values, and we calculated the RSME and EA (\%) of each group. As can be seen from Table 6, the determined coefficient of the estimation model based on textural features is better than that based on spectral and topographic features, the determined coefficient of the estimation model based on spectral, topographic, and textural features is significantly improved, and the estimation accuracy is greatly improved.

Table 6. Comparison of measured and estimated results of the three models

\begin{tabular}{c|c|c|c|c}
\hline Data & Fitting equation & $\mathbf{R}^{\mathbf{2}}$ & RMSE & EA (\%) \\
\hline \multirow{3}{*}{ GF-2 $(1 \mathrm{~m})$} & $\mathrm{y}=0.6418 \mathrm{x}+0.2543$ & 0.723 & 0.123 & 84.11 \\
& $\mathrm{y}=1.181 \mathrm{x}-0.1929$ & 0.761 & 0.096 & 87.41 \\
& $\mathrm{y}=1.1919 \mathrm{x}-0.2017$ & 0.868 & 0.079 & 89.82 \\
\hline \multirow{3}{*}{ GF-1 (8 m) } & $\mathrm{y}=0.7858 \mathrm{x}+0.1757$ & 0.699 & 0.132 & 81.11 \\
& $\mathrm{y}=0.5068 \mathrm{x}+0.3883$ & 0.676 & 0.110 & 84.28 \\
& $\mathrm{y}=0.5564 \mathrm{x}+0.3211$ & 0.784 & 0.132 & 87.28 \\
\hline \multirow{3}{*}{ GF- 1(16 m) } & $\mathrm{y}=0.7374 \mathrm{x}+0.0452$ & 0.587 & 0.167 & 76.86 \\
& $\mathrm{y}=0.8297 \mathrm{x}+0.0359$ & 0.652 & 0.117 & 83.75 \\
& $\mathrm{y}=0.6282 \mathrm{x}+0.2453$ & 0.708 & 0.104 & 85.67 \\
\hline \multirow{3}{*}{ Landsat OLI (30 m) } & $\mathrm{y}=0.6317 \mathrm{x}+0.2502$ & 0.516 & 0.101 & 85.61 \\
& $\mathrm{y}=0.7266 \mathrm{x}+0.2033$ & 0.527 & 0.097 & 86.15 \\
& $\mathrm{y}=0.8489 \mathrm{x}+0.1052$ & 0.621 & 0.092 & 86.87 \\
\hline
\end{tabular}

\section{Object-oriented classification}

According to the image features in the study area and the actual survey results for GF-2 $(1 \mathrm{~m})$, GF-1 $(8 \mathrm{~m})$, GF-1 $(16 \mathrm{~m})$, and Landsat $8(30 \mathrm{~m})$, these four kinds of images were segmented at multiple scales. We selected the image objects at the optimal segmentation scale and established classification levels. We used the NNC, SVM, and CART methods to classify the forest land. According to the classification standards and the actual conditions of the study area, with reference to land-use classification standards, we divided the ground objects within the study area into six categories, including buildings, water, shrub land, grassland, bare land, and forest. We then divided the forest land into dense forest land, middle wood land, and sparse wood land according to the degree of canopy closure. Figure 6 shows the results of classification based on four kinds of images using NNC, SVM, and CART methods, respectively, a1, a2, a3, a4 are the results of using CART classifier; b1, b2, b3, b4 are the results of using $\mathrm{NNC}$ classifier; c1, c2, c3, c4 are the results of using SVM classifier.

The evaluation of accuracy is a key step in remote-sensing image classification. In this study, we selected a total of 200 sample verification points in the study area to evaluate the accuracy of the three image-classification methods. To calculate their accuracies, we constructed a confusion matrix. The selected sample verification points were mainly derived from field sampling points, drone aerial sampling points, a distribution map of a second-class survey of forest resources, and forest phase maps of the study area. Tables 5-8 list the classification accuracies of these methods for GF-2 (1 m), GF-1 (8 m), GF-1 (16 m), and Landsat 8 (30 m) images, respectively. 


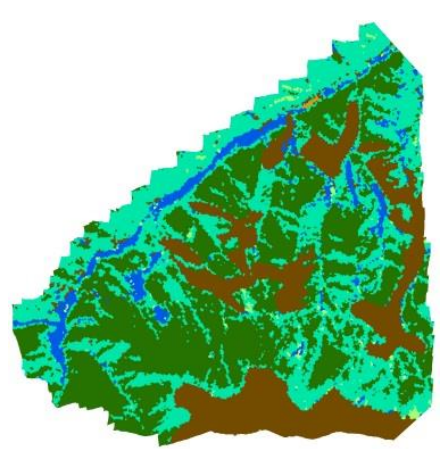

(a1)

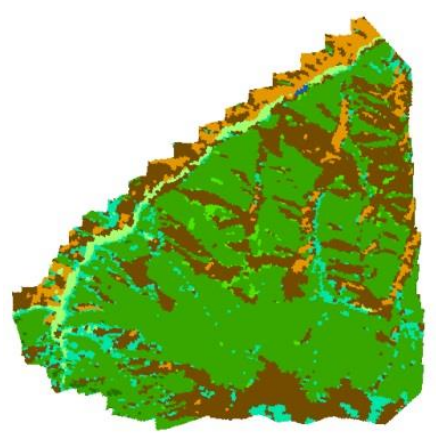

(a2)

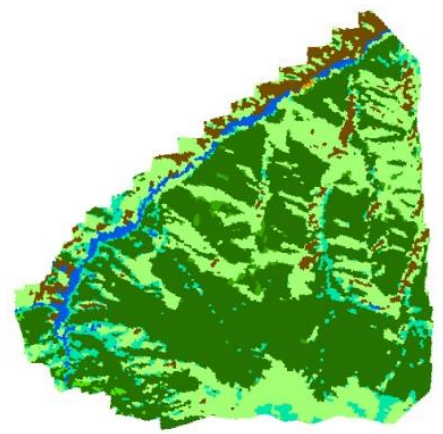

(a3)

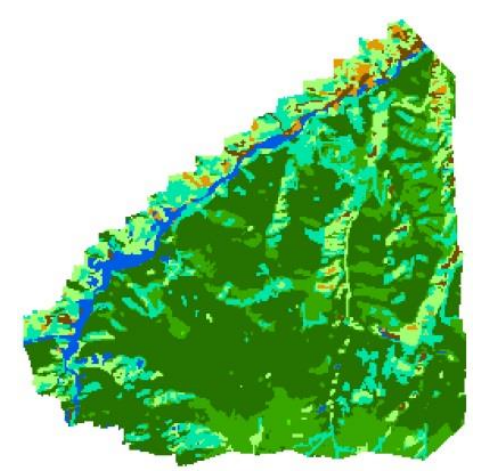

(a4)

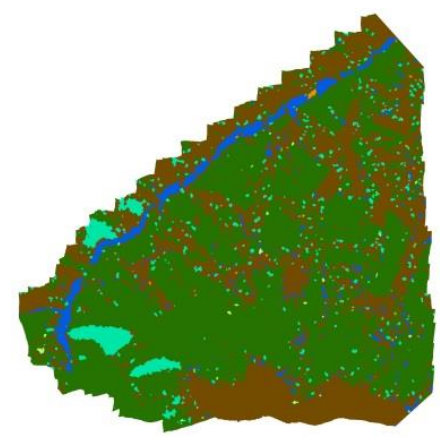

(b1)

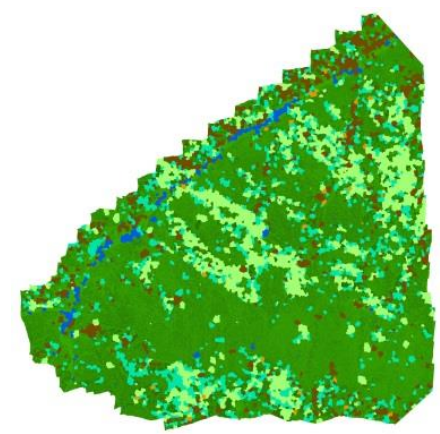

(b2)

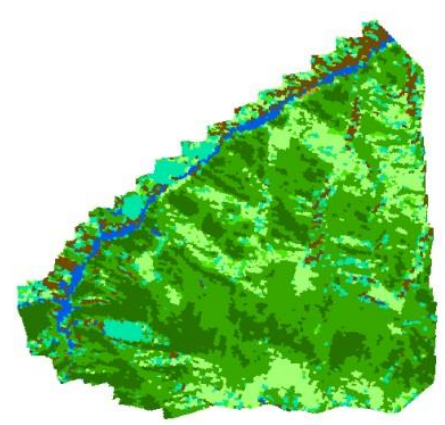

(b3)

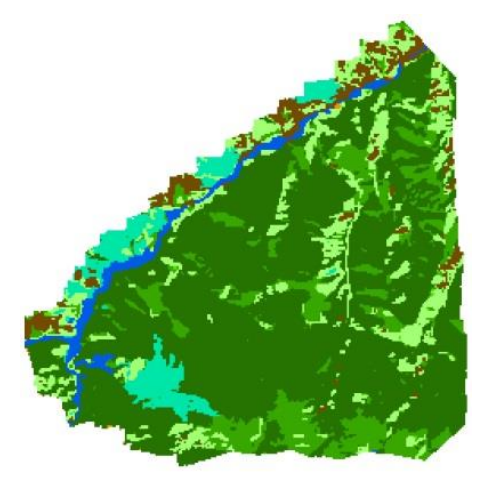

(b4)

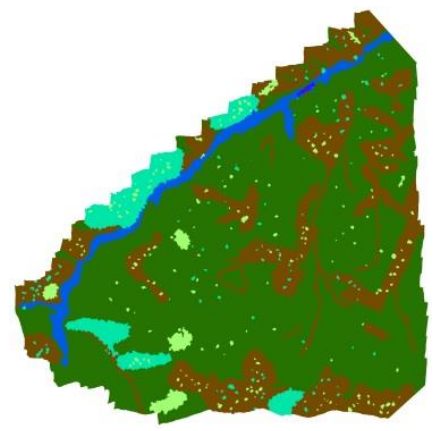

(c1)

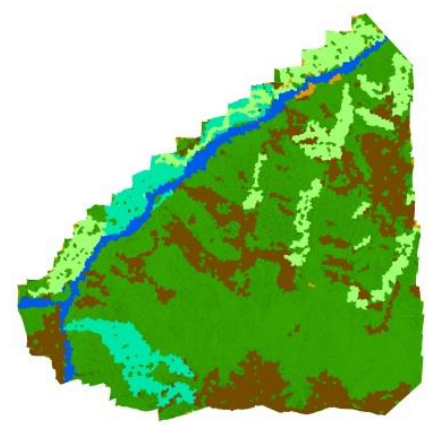

(c2)

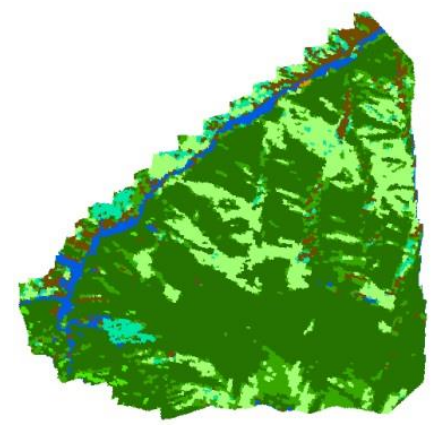

(c3)

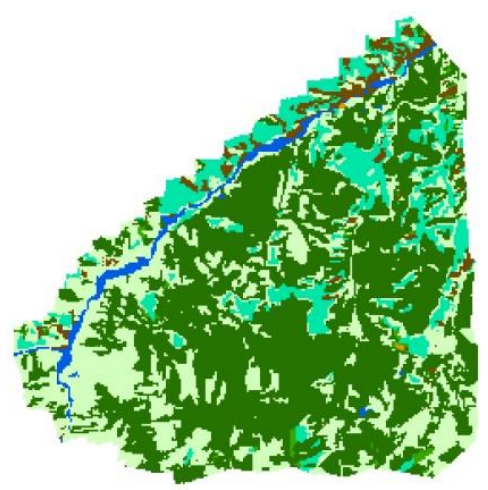

(c4)

Legend

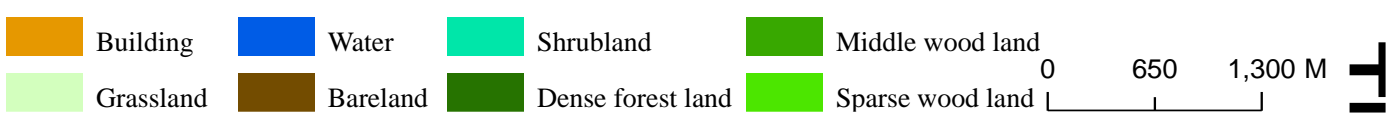

Figure 6. Classification results of different classifiers. al, a2, a3, a4: CART; b1, b2, b3, b4: NNC; c1, c2, c3, c4: SVM; al, b1, c1 from GF-2 (1 m), a2, b2, c2 from GF-1 (8 m), a3, b3, c3 from GF-1 (16 m), a4, b4, c4 from Landsat 8 OLI $(30 \mathrm{~m})$ 
As shown in Table 7, in terms of overall accuracy, the classification accuracy of the SVM method was $84.50 \%$, which is better than those of the other two classification methods. This result demonstrates that classification based on the SVM method is more suitable for forest land classification of GF-2 $(1 \mathrm{~m})$ remote-sensing images. Regarding SVM's classification accuracy for different land types, the classification accuracies of buildings and sparse forests were the best, and those of middle and dense forests were good. The best classification result for middle and dense forests were also obtained by the SVM method, with user accuracies of $96.67 \%$ and $85.71 \%$ and mapping accuracies of $90.63 \%$ and $73.0 \%$, respectively.

Table 7. Accuracies of three classification methods of GF-2 $(1 \mathrm{~m})$

\begin{tabular}{c|c|c|c|c|c|c}
\hline \multirow{2}{*}{ Type } & \multicolumn{2}{|c|}{ NNC } & \multicolumn{2}{c|}{ CART } & \multicolumn{2}{c}{ SVM } \\
\cline { 2 - 7 } & UA & PA & UA & PA & UA & PA \\
\hline Building & 100.00 & 100.00 & 100.00 & 100.00 & 100.00 & 100.00 \\
Grassland & 84.00 & 70.00 & 100.00 & 33.33 & 91.67 & 73.33 \\
Water & 100.00 & 100.00 & 63.64 & 100.00 & 87.50 & 100.00 \\
Bare land & 43.33 & 100.00 & 27.78 & 38.46 & 42.31 & 84.62 \\
Shrub land & 42.86 & 37.50 & 17.95 & 87.50 & 38.46 & 62.50 \\
Dense forest land & 93.44 & 89.06 & 94.64 & 82.81 & 96.67 & 90.63 \\
Middle wood land & 71.43 & 41.67 & 100.00 & 66.67 & 85.71 & 73.00 \\
Sparse wood land & 100.00 & 100.00 & 100.00 & 100.00 & 100.00 & 100.00 \\
\hline OA & \multicolumn{3}{|c|}{82.50} & \multicolumn{2}{c}{72.50} & \multicolumn{2}{c}{84.50} \\
\hline
\end{tabular}

For the GF-1 $(8 \mathrm{~m})$ image classification, the SVM method also achieved a higher accuracy of $84.01 \%$, which is $10 \%$ higher than that of the other two methods. When classifying middle and dense forests, the classification result for dense forest was relatively good, but that for middle forest was poor. Better classification results for dense forests was achieved by the CART and SMV methods, with user accuracies of $93.70 \%$ and $93.02 \%$ and mapping accuracies of $92.97 \%$ and $93.75 \%$, respectively. In the classification of bare land, the NNC method obtained relatively good results, with a user and mapping accuracies of $64.29 \%$ and $69.23 \%$, respectively (Table 8). The SVM method achieved better recognition of shrub land, with user and mapping accuracies of $71.43 \%$ and $62.50 \%$, respectively.

Table 8. Accuracies of three classification methods for GF-1 (8 m)

\begin{tabular}{c|c|c|c|c|c|c}
\hline \multirow{2}{*}{ Type } & \multicolumn{2}{|c|}{ NNC } & \multicolumn{2}{c|}{ CART } & \multicolumn{2}{c}{ SVM } \\
\cline { 2 - 7 } & UA & PA & UA & PA & UA & PA \\
\hline Buildings & 100.00 & 100.00 & 100.00 & 100.00 & 100.00 & 100.00 \\
Grassland & 73.68 & 46.67 & 66.67 & 53.33 & 76.92 & 66.67 \\
Water & 100.00 & 100.00 & 66.67 & 85.71 & 77.78 & 100.00 \\
Bare land & 64.29 & 69.23 & 35.71 & 38.46 & 50.00 & 61.54 \\
Shrub land & 16.67 & 75.00 & 35.71 & 62.50 & 71.43 & 62.50 \\
Dense forest land & 87.93 & 79.69 & 93.70 & 92.97 & 93.02 & 93.75 \\
Middle wood land & 100.00 & 50.00 & 60.00 & 50.00 & 54.55 & 50.00 \\
Sparse wood land & 100.00 & 100.00 & 100.00 & 100.00 & 100.00 & 100.00 \\
\hline OA & \multicolumn{2}{|c|}{73.00} & \multicolumn{2}{c}{79.50} & \multicolumn{2}{c}{84.01} \\
\hline
\end{tabular}


For GF-1 (16 m) images, the classification of sparse forest land by the SVM method was also the best. The classification accuracy of the SVM method for dense forest was higher than that for middle-closed forest land for both user and mapping accuracy, i.e., higher than $80 \%$ (Table 9). The NNC method made obvious misclassifications and misjudgments in this category, which also occurred for bare land and shrub land, yielding only a fair classification accuracy.

Table 9. Accuracy of three classification methods for GF-1 (16 m)

\begin{tabular}{c|c|c|c|c|c|c}
\hline \multirow{2}{*}{ Type } & \multicolumn{2}{|c|}{ NNC } & \multicolumn{2}{c|}{ DTC } & \multicolumn{2}{c}{ SVM } \\
\cline { 2 - 7 } & UA & PA & UA & PA & UA & PA \\
\hline Buildings & 100.00 & 100.00 & 100.00 & 100.00 & 100.00 & 100.00 \\
Grassland & 60.00 & 50.00 & 42.86 & 70.00 & 50.00 & 46.67 \\
Water & 100.00 & 100.00 & 100.00 & 85.71 & 77.78 & 80.00 \\
Bare land & 57.14 & 61.54 & 42.86 & 46.15 & 50.00 & 53.85 \\
Shrub land & 31.25 & 62.50 & 39.41 & 62.50 & 66.67 & 50.00 \\
Dense forest land & 96.10 & 57.81 & 89.62 & 74.22 & 88.89 & 81.25 \\
Middle wood land & 48.62 & 41.67 & 33.33 & 16.67 & 49.17 & 58.33 \\
Sparse wood land & 50.00 & 100.00 & 50.00 & 100.00 & 100.00 & 100.00 \\
\hline OA & \multicolumn{3}{|c|}{58.00} & \multicolumn{3}{c|}{72.00} \\
\hline
\end{tabular}

For Landsat $8(30 \mathrm{~m})$ images, in terms of overall accuracy (Table 10), the NNC classification accuracy was $73.50 \%$. Compared with the CART and SVM methods, the NNC accuracy was $4.5 \%$ and $12 \%$ higher, respectively, which indicates that the NNC method is more suitable for forest land classification in the area. Regarding the classification accuracy for different land types, those for buildings and sparse forests were the best, and that for moderately closed forest land was fair. The classification accuracy of dense forest by NNC was the best, with user and mapping accuracies of $92.44 \%$ and $85.94 \%$, but the classification accuracies of bare land and shrub land were low.

Table 10. Accuracy of three classification methods of Landsat $8(30 \mathrm{~m})$

\begin{tabular}{c|c|c|c|c|c|c}
\hline \multirow{2}{*}{ Type } & \multicolumn{2}{|c|}{ NNC } & \multicolumn{2}{c|}{ CART } & \multicolumn{2}{c}{ SVM } \\
\cline { 2 - 7 } & UA & PA & UA & PA & UA & PA \\
\hline Buildings & 100.00 & 100.00 & 100.00 & 100.00 & 100.00 & 100.00 \\
Grassland & 46.43 & 43.33 & 42.86 & 40.00 & 23.73 & 46.67 \\
Water & 63.64 & 100.00 & 77.78 & 100.00 & 100.00 & 100.00 \\
Bare land & 55.56 & 38.46 & 83.33 & 38.46 & 55.56 & 38.46 \\
Shrub land & 33.33 & 50.00 & 22.00 & 37.50 & 27.14 & 22.50 \\
Dense forest land & 92.44 & 85.94 & 92.86 & 81.25 & 88.79 & 74.22 \\
Middle wood land & 31.58 & 50.00 & 25.00 & 41.67 & 50.00 & 48.33 \\
Sparse wood land & 100.00 & 100.00 & 100.00 & 100.00 & 100.00 & 100.00 \\
\hline OA & \multicolumn{2}{|c|}{73.50} & \multicolumn{2}{c|}{69.00} & \multicolumn{2}{c}{62.50} \\
\hline
\end{tabular}

In summary, in terms of overall classification accuracy, the best classification effect was achieved for GF-2 $(1 \mathrm{~m})$ remote-sensing images, and the worst for Landsat 8 
$(30 \mathrm{~m})$ remote-sensing images. The overall classification accuracies for the GF-1 $(8 \mathrm{~m})$ and GF-1 (16 m) images were $78.83 \%$ and $66.17 \%$, respectively, which indicates that the classification accuracy of forest land in the study area depends to some degree on the spatial resolution of the image. Regarding classification methods, when using the CART method for classification, the overall classification accuracies for GF-2 $(1 \mathrm{~m})$, GF-1 $(8 \mathrm{~m}), \mathrm{GF}-1(16 \mathrm{~m})$, and Landsat $8(30 \mathrm{~m})$ remote-sensing images were $72.50 \%$, $79.50 \%, 68.00 \%$, and $69.00 \%$, respectively. However, the classification method that is most suitable for the study area varies with the data source. In terms of GF-2 (1 m) images, our results indicate that the best classification for this study area is the SVM method, followed by the NNC and CART methods. For GF-1 $(8 \mathrm{~m})$ and GF-1 (16 m) images, the best classification method was SVM, followed by NNC. For Landsat 8 $(30 \mathrm{~m})$ images, the best to worst classification methods are the NNC, CART, and SVM methods.

\section{Discussion}

\section{Superiority and summary}

High-precision land use/cover remote sensing classification mapping is widely used in precision agriculture, vegetation ecology, wetland water quality, urban heat island, mineral resources, atmospheric environment, and other research fields. In this study, multi-source data was based on agreement analysis and refined classification (Jung et al., 2006). Compared with traditional remote sensing forest land classification methods, the object-oriented method can not only make full use of the spectral information of remote sensing images, but also can add texture information, shape information, and custom information according to the classification of ground features to more accurately compare effective extraction and classification of target features (Judah and Hu, 2019). In the case of determining the optimal segmentation scale, the selection of remotely sensed images that do not use spatial resolution and the use of different object-oriented classifiers will have a certain impact on the classification effect. Therefore, a reasonable selection of remotely sensed images to determine the spatial resolution of data and classification method has become the key to the fine classification of forest land types.

From the perspective of the spatial resolution of remote sensing images, when the resolutions of remote sensing images are $1 \mathrm{~m}, 8 \mathrm{~m}, 16 \mathrm{~m}$, and $30 \mathrm{~m}$, their average overall classification accuracy is $80.00 \%, 78.83 \%, 66.17 \%$ and $68.33 \%$ It shows that the higher the resolution, the higher the classification accuracy of the image. This is because the high-resolution images contain more feature information and categories, and the information utilization rate is higher, which leads to the improvement of the classification accuracy of the image. However, in practical applications, although the classification of images with a resolution of $1 \mathrm{~m}$ and $8 \mathrm{~m}$ is good, but because of the large amount of data it contains, the processing time is long, and the process is more complicated, you can choose to ensure certain accuracy Fast processing speed of $16 \mathrm{~m}$ and $30 \mathrm{~m}$ images.

From the perspective of the classification method, the classification method that is most suitable for the study area varies with different data sources. For example, in the GF-2 $(1 \mathrm{~m})$ remote sensing image, the classification effect of the study area is better by the support vector machine method, followed by the nearest neighbor method and the decision tree method; for the medium resolution GF-1 (8 m), GF-1 (16 m) remote sensing image, the effect is better is support vector machine, the worst is the nearest 
neighbor method; in Landsat8 $(30 \mathrm{~m})$ remote sensing image, the classification effect is the nearest neighbor classification, decision tree classification Support vector machine method.

This is due to a series of reasons such as different study areas, different image data sources, and the scale selected during segmentation. As a result, for each data source, the forest land classification method that is most suitable for the region is different. Due to the particularity of geographical location and terrain in this study area, the distribution of forest stands is complex. Different classification methods have been adopted for different data sources. It can be seen from the accuracy analysis that the adopted classification method has certain effectiveness and reliability, which meets the requirements for extraction of Picea Schrenkiana var. tianshanica (PSVT).

\section{Limitation and outlook}

This study comprehensively uses the spectrum, terrain, texture, shape and other information contained in the image to estimate the canopy closure model and forest land classification of the study area (Amani et al., 2017; Dendoncker et al., 2007), which has certain limitations. (1) The study area is small, and large-scale verification and improvement are needed in other areas to ensure the universality of the estimation model. (2) The accuracy of results is affected by landscape heterogeneity in the study area. Therefore, although this research has made important progress in remote sensing classification mapping of land use/cover based on multi-source data, many follow-up studies need to be completed to obtain the best results. (3) In the future more attention should be paid to the fusion between different classifiers, because it is difficult for a single type of classifier to classify all the forest types better.

For example, the target classification system can be further refined. This study divided PSVT into eight main types: building, water, shrubland, middle woodland, grassland, bareland, dense woodland, sparse woodland. Specifically, these types are high generalizations of actual land types, avoiding as much confusion as possible due to the complexity of classification. However, in view of the particularity of forest areas, reasonable attention should be paid to PSVT resources in follow-up studies.

\section{Conclusions}

Taking GF-2 (1 m), GF-1 (8 m), GF-1 (16 m), Landsat 8 (30 m) images combined with field survey data, and performed multi-resolution segmentation to select the best segmentation scales. Based on the spectrum, texture and terrain factors, the canopy closure inversion of PSVT was performed to select the characteristic factors suitable for different images. Then, we applied three object-oriented methods (i.e. the support vector machine (SVM), classification and regression tree (CART), and the nearest neighbor classification (NNC) methods) to classify the forest land. The conclusions show that (1) the near-infrared (NIR) band is highly independent and makes an important contribution to the optimum index factor (OIF), in which the real-time adjustments of segmentation results are made to achieve better effect. (2) In the canopy-closure estimation model, a combination of the spectrum, terrain remote-sensing factors, and textural feature factors yields the best result. For GF-2 $(1 \mathrm{~m})$ images, the combination of the four characteristic factors SI, $\mathrm{Con}_{2}, \mathrm{Con}_{3}$, and Con 4 yields the best estimation model. The model estimation accuracy is an EA of $89.82 \%$, an RMSE of 0.079 , and a determination coefficient $\mathrm{R}^{2}$ of 0.868. (3) In terms of GF-2 images, the classification performs better when using the 
SVM method, which achieved an overall classification accuracy of $84.5 \%$, thereby being an effective classification method for the forest land types in the study area. In terms of their economics and practicality, each data source has its own advantages.

Additionally, forest canopy estimation algorithm can be further developed. As there are many variables introduced, and there is a strong correlation between the texture feature factors, it is important to find a reasonable and effective modeling method. With the improvement of image resolution, the influence of the shadow index on the estimation of occlusion is getting larger and larger. Due to the differences in the selected remote sensing images or the differences in the ecological and geographical environments in different regions, the factors for estimating canopy closure in different regions should take into account the actual local conditions.

Acknowledgments. This research was funded by the National Key Research and Development Program of China (grant number 2016YFB0501403).

Conflict of interests. The authors declare that they have no conflicts of interests.

\section{REFERENCES}

[1] Abdulhakim, M. A. (2019): Land cover and land use classification performance of machine learning algorithms in a boreal landscape using Sentinel-2 data. - GIScience \& Remote Sensing 57(1): 1-20.

[2] Adepoju, K. A., Adelabu, S. A. (2020): Improving accuracy evaluation of Landsat-8 OLI using image composite and multisource data with Google Earth Engine. - Remote Sensing Letters 11(2): 107-116.

[3] Aizezitiyuemaier, M., Yusufujiang, R., He, H., Baihetinisha, A. (2019): Spatio-temporal characteristics of vegetation water use efficiency and its relationship with climate factors in Tianshan Mountains in Xinjiang from 2000 to 2017. - Chinese Journal of Plant Ecology 43(6): 490-500.

[4] Amani, M., Salehi, B., Mahdavi, S., Granger, J., Brisco, B. (2017): Wetland classification in Newfoundland and Labrador using multi-source SAR and optical data integration. GIscience \& Remote Sensing 54(6): 779-796.

[5] Baatz, M., Schape, A. (2000): Multiresoulution segmentation: an optimization approach for high quality mufti scale image segmentation. - Angewandte Geographische Informationsverarbeitung 12(12): 12-23.

[6] Brabant, C., Alvarez-Vanhard, E., Laribi, A., Morin, G., Nguyen, K. T., Thomas, A., Houet, T. (2019): Comparison of hyperspectral techniques for urban tree diversity classification. - Remote Sensing 11(11): 1-19.

[7] Cai, G. Y., Ren, H. Q., Yang, L. Z., Zhang, N., Du, M. Y., Wu, C. S. (2019): Detailed urban land use land cover classification at the metropolitan scale using a three-layer classification scheme. - Sensors 19(14): 1-24.

[8] Dendoncker, N., Rounsevell, M., Bogaert, P. (2007): Spatial analysis and modelling of land use distributions in Belgium. - Computers, Environment and Urban Systems 31(2): 188-205.

[9] Donato, D. C., Halofsky, J. S., Reilly, M. J. (2019): Corralling a black swan: natural range of variation in a forest landscape driven by rare, extreme events. - Ecological Applications 30(1): 1-16.

[10] Dilixiati, M., Rusuli, Y., Namaiti, H. (2019): The phenological characteristics and climatic response of vegetation in the Xinjiang Tianshan Mountains, China. - Climate Change Research 15(6): 624-632. 
[11] Fernandez-Guisuraga, J. M., Suarez-Seoane, S., Calvo, L. (2019): Modeling Pinus pinaster forest structure after a large wildfire using remote sensing data at high spatial resolution. - Forest Ecology and Management 446: 257-271.

[12] Gilcher, M., Ruf, T., Emmerling, C., Udelhoven, T. (2019): Remote sensing based binary classification of maize. dealing with residual autocorrelation in sparse sample situations. - Remote Sensing 11(18): 2172.

[13] Goodchild, M. F. (1995): Attribute accuracy elements of spatial data quality by Guptill and Morrison. - International Cartographic Association 37(9): 59-79.

[14] Guo, Y. G., Yu, X. F., Jiang, D., Wang, S. K., Jiang, X. S. (2012): Study on forest classification based on object oriented techniques. - Journal of geo-information science 14(4): 514-522.

[15] Haralick, R. M., Shanmugam, K., Dinstein, I. (1973): Textural features for image classification. - IEEE transactions on systems man and cybernetics SCM-3: 610-621.

[16] Hofmann, P. (2001): Detecting informal settlements from IKONOS image data using methods of object oriented image analysis-an from cape town. - Urban Remote Sensing 20(12): 85-88.

[17] Judah, A., Hu, B. X. (2019): The integration of multi-source remotely-sensed data in support of the classification of wetlands. - Remote Sensing 11(13): 1537.

[18] Jung, M., Henkel, K., Herold, M., Churkina, G. (2006): Exploiting synergies of global land cover products for carbon cycle modeling. - Remote Sensing of Environment 101(4): 534-553.

[19] Li, Q., Wang, Z. X., Wang, Y. P., Liu, M. T., Yang, Y. Q. (2019): Study on canopy density inversion of Picea schrenkiana forest based on GF-2 remote sensing image. Journal of Central South University of Forestry \& Technology 39(8): 48-54.

[20] Lin, W. H., Yang, Y. Q., Hou, C. M. (2004): A study of spectral features of stands and their related factors with principal component analysis. - Journal of South China Agricultural University (Natural Science Edition) 25(2): 22-25.

[21] Liu, M. T., Wang, Z. X., Wang, Y. P., Li, Q., Shi, Y. X. (2019): Plant communities pattern of Picea tianschanica forest and their interrelations with environmental factors in Tianshan area. - Forest Research 32(6): 90-98.

[22] Maas, A. E., Rottensteiner, F., Heipke, C. (2019): A label noise tolerant random forest for the classification of remote sensing data based on outdated maps for training - Computer Vision and Image Understanding 188: 1-18.

[23] Perea-Ardila, M. A., Oviedo-Barrero, F., Leal-Villamil, J. (2019): Mangrove forest mapping through remote sensing imagery: study case for Buenaventura, Colombia. Revista De Teledeteccion 53: 73-85.

[24] Piazza, G. A., Vibrans, A. C., Liesenberg, V., Refosco, J. C. (2016): Object-oriented and pixel-based classification approaches to classify tropical successional stages using airborne high spatial resolution image. - Remote Sensing 53(2): 11-21.

[25] Rajasekhar, M., Raju, G. S., Raju, R. S., Ramachandra, M., Kumar, B. P. (2019): Accuracy assessment of land use/land cover classification in parts of Kadapa district (Andhra Pradesh, India), using remote sensing and GIS. - Journal of Indian Geophysical Union 23(4): 356-366.

[26] Singh, P. P., Garg, R. D. (2013): Information extraction from high resolution satellite imagery using integration technique. - Communications in Computer and Information Science 276: 231-245.

[27] Sun, X. D. (2009): Object-oriented forestry land extraction based on semantic correlation. - Journal of Fujian Forestry Science and Technology 36(3): 36-40.

[28] Twisa, S., Buchroithner, M. E. (2019): Land-use and land-cover (LULC) change detection in Wami River basin, Tanzania. - Land 8(9): 136.

[29] Wang, X. X., Gao, X. W., Zhang, Y. Z., Fei, X. W., Chen, Z., Wang, J., Zhang, Y. Y., Lu, X., Zhao, H. M. (2019): Land-cover classification of coastal wetlands using the RF algorithm for Worldview-2 and Landsat 8 images. - Remote Sensing 11(16): 1927. 
[30] Wei, Y. F., Tong, X. H., Chen, G., Liu, D. Q., Han, Z. F. (2019): Remote detection of large-area crop types: the role of plant phenology and topography. - Agriculture 9: 150.

[31] Zhang, L., Jia, K., Li, X. S., Yuan, Q. Z., Zhao, X. F. (2014): Multi-scale segmentation approach for object-based land-cover classification using high-resolution imagery. Remote Sensing Letters 5(1): 73-82.

[32] Zhang, X. L., Feng, X. Z., Xiao, P. F. (2015): Multi-scale segmentation of high spatial resolution remote sensing images using adaptively increased scale parameter. Photogrammetric Engineering and Remote Sensing 81(6): 461-470.

\section{APPENDIX}

Table A1. The attribute table of field survey samples

\begin{tabular}{|c|c|c|c|c|}
\hline Site & Longitude $\left({ }^{\circ}\right)$ & Latitude $\left({ }^{\circ}\right)$ & Elevation (m) & Slope $\left(^{\circ}\right)$ \\
\hline 1 & 86.838 & 43.403 & 1959.28 & 33.34 \\
\hline 2 & 86.839 & 43.399 & 1786.17 & 1.19 \\
\hline 3 & 86.848 & 43.398 & 1951.00 & 43.69 \\
\hline 4 & 86.829 & 43.398 & 1890.05 & 68.49 \\
\hline 5 & 86.833 & 43.395 & 1793.27 & 3.52 \\
\hline 6 & 86.834 & 43.394 & 1861.85 & 52.39 \\
\hline 7 & 86.843 & 43.393 & 1987.05 & 60.01 \\
\hline 8 & 86.826 & 43.390 & 1877.12 & 26.90 \\
\hline 9 & 86.816 & 43.386 & 1870.91 & 39.76 \\
\hline 10 & 86.807 & 43.385 & 1844.58 & 25.71 \\
\hline 11 & 86.833 & 43.384 & 2028.59 & 21.07 \\
\hline 12 & 86.821 & 43.383 & 1902.19 & 51.62 \\
\hline 13 & 86.820 & 43.382 & 1889.79 & 16.32 \\
\hline 14 & 86.814 & 43.380 & 2134.94 & 66.23 \\
\hline 15 & 86.801 & 43.379 & 1836.07 & 7.34 \\
\hline 16 & 86.798 & 43.378 & 1837.18 & 1.63 \\
\hline 17 & 86.804 & 43.378 & 1944.42 & 26.03 \\
\hline 18 & 86.807 & 43.378 & 2056.10 & 19.65 \\
\hline 19 & 86.841 & 43.378 & 2061.99 & 37.98 \\
\hline 20 & 86.830 & 43.377 & 2078.59 & 35.17 \\
\hline 21 & 86.812 & 43.377 & 2151.87 & 38.58 \\
\hline 22 & 86.806 & 43.376 & 2027.58 & 33.40 \\
\hline 23 & 86.797 & 43.376 & 1914.21 & 28.05 \\
\hline 24 & 86.813 & 43.376 & 2187.08 & 55.85 \\
\hline 25 & 86.792 & 43.376 & 1886.56 & 44.32 \\
\hline 26 & 86.807 & 43.374 & 2049.24 & 27.76 \\
\hline 27 & 86.823 & 43.373 & 2168.12 & 77.74 \\
\hline 28 & 86.795 & 43.371 & 1921.97 & 57.97 \\
\hline 29 & 86.826 & 43.371 & 2238.82 & 34.35 \\
\hline 30 & 86.806 & 43.371 & 2106.82 & 34.82 \\
\hline 31 & 86.816 & 43.370 & 2158.13 & 46.48 \\
\hline 32 & 86.797 & 43.369 & 1989.59 & 36.31 \\
\hline 33 & 86.804 & 43.367 & 2210.87 & 51.00 \\
\hline
\end{tabular}




\begin{tabular}{l|l|l|l|l}
34 & 86.841 & 43.367 & 2203.04 & 46.69 \\
35 & 86.788 & 43.366 & 2060.14 & 24.80 \\
36 & 86.832 & 43.365 & 2162.08 & 26.23 \\
37 & 86.812 & 43.365 & 2213.90 & 67.97 \\
38 & 86.794 & 43.364 & 2164.53 & 46.44 \\
39 & 86.821 & 43.361 & 2315.67 & 2.88 \\
40 & 86.846 & 43.361 & 2261.91 & 28.68 \\
41 & 86.804 & 43.359 & 2255.38 & 24.79 \\
42 & 86.780 & 43.358 & 2063.56 & 42.75 \\
43 & 86.795 & 43.357 & 2251.45 & 55.42 \\
44 & 86.835 & 43.356 & 2379.38 & 33.86 \\
45 & 86.814 & 43.353 & 2513.09 & 52.06 \\
46 & 86.825 & 43.350 & 2523.30 & 41.09 \\
47 & 86.795 & 43.348 & 2511.50 & 55.02 \\
\hline
\end{tabular}

